\title{
Unemployment dynamics in Uruguay: an analysis using chain reaction theory ${ }^{1}$
}

\author{
Martín Leites and Sylvina Porras
}

\section{Abstract}

This article analyses unemployment dynamics in Uruguay within the framework of chain reaction theory and offers evidence to account for the remarkable drop in unemployment over recent years. It confirms the impact of exogenous variables on the long-run trajectory of unemployment and rules out the notion that its long-run level gravitates around an equilibrium value. It identifies inertia processes in labour supply and demand and in wages, whose mutual interactions mean that shocks have persistent effects on unemployment. There are also complementary spillover effects that influence the magnitude and duration of the effects of shocks. Lastly, the article emphasizes that growth in the capital stock and capital productivity accounts for some of the substantial decline in unemployment in Uruguay since 2003.

\section{Keywords}

Unemployment, labour market, labour supply, wages, measurement, Uruguay

\section{JEL classification}

$$
\text { J21, J23, J64 }
$$

\section{Authors}

Martín Leites is a researcher at the Institute of Economics of the University of the Republic, Uruguay.mleites@iecon.ccee.edu.uy

Sylvina Porras is a researcher at the Institute of Economics of the University of the Republic, Uruguay. sylvina@iecon.ccee.edu.uy

1 The authors are grateful to Verónica Amarante for reviewing and providing valuable comments on an earlier version of this document. 


\section{Introduction}

The unemployment rate in Uruguay dropped by 12 percentage points between 2002 and 2011, and in recent years has remained at levels that are historically low relative to long-run performance. This suggests a degree of inertia in its dynamics, casts doubt on the existence of a natural rate of unemployment and raises questions about the factors explaining this process. In particular, the matter of how the evolution of long-run unemployment is connected to capital accumulation takes on considerable importance, as this variable became very dynamic in the period, increasing the country's production capacity. Figure 1 shows that in the late 1990s the dynamics of gross fixed capital formation began to move symmetrically relative to the unemployment rate. This suggests the hypothesis that this non-labour market variable could explain some of the drop in the unemployment rate through its positive impact on the demand for labour.

Figure 1

Gross fixed capital formation and unemployment, 1997-2011 (Billions of 2005 pesos and percentages)

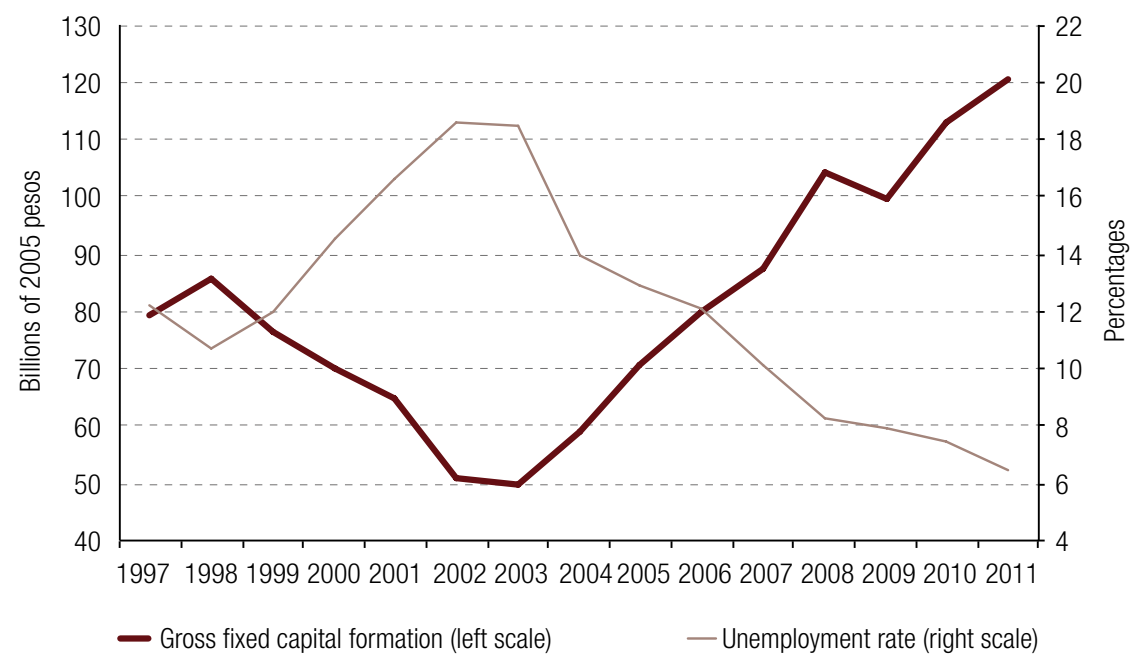

Source: Prepared by the authors, on the basis of data from the National Institute of Statistics (INE) and the Central Bank of Uruguay.

Earlier works studying unemployment dynamics in Uruguay used the most standard approaches in the economic literature: the natural unemployment rate approach and the hysteresis hypothesis. Their findings do not conclusively show the existence of a natural rate of unemployment, and while demonstrating a degree of inertia, they do not provide evidence for the factors determining its evolution. The approaches used in these studies have three essential limitations: (i) they operate with one-equation models; (ii) they do not serve to link short- and long-run behaviour, and (iii) they rule out the introduction of trend variables to explain unemployment.

The purpose of the present study is to explain unemployment dynamics in Uruguay during the period from 1985 to 2011 by applying chain reaction theory, which has some advantages over more extended methods in answering the questions raised. This approach is more general and, instead of assuming that unemployment will converge on an equilibrium level or that the effect of shocks will be persistent (hysteresis), suggests a model for evaluating both hypotheses empirically. Second, it is less restrictive and can be used to identify the effects on the unemployment rate of shocks from variables that are exogenous to the labour market. According to Bande and Karanassou (2009), one of the key advantages of chain reaction theory is that it enables the effects of capital stock changes on the 
unemployment rate to be evaluated empirically in both the short and the long run. This is in contrast to the standard approaches, which are emphatic that shifts in the capital trajectory have no long-term effect on the unemployment rate (Layard, Nickell and Jackman, 1991).

Third, it offers a comprehensive perspective connecting the evolution of short-run unemployment to its long-run trend. This makes it possible to identify the adjustment mechanisms operating in the labour market, evaluate the persistence of a temporary shock's effects and analyse how variables exogenous to the labour market, and the interaction of these with supply and demand adjustment processes (spillover effects), can have persistent or permanent effects on long-run unemployment.

To the best of the authors' knowledge, this approach has not been used to study unemployment in developing countries. Certain characteristics of labour markets in the region's countries, such as informality and the level of segmentation, and likewise their remarkable recent dynamism, make it well worth applying (Weller, 2014; World Bank, 2012). Uruguay is no exception, having had historically low levels of unemployment recently by both its own and regional standards, which makes it important to ascertain how unemployment dynamics have been affected by the following: (i) the presence of inertia factors; (ii) variables exogenous to the labour market; (iii) spillover effects, and (iv) the complementarity of adjustment processes. Having evidence on these aspects will contribute to a better understanding of the dynamics of unemployment and make it possible to identify the main determinants of its recent decline. In particular, this study provides evidence for the effects of capital accumulation and labour productivity on the drop in unemployment, variables that Weller (2014) suggests could express the importance of the production context in explaining the dynamism of employment. Furthermore, it indirectly captures the way the production context interacts with institutional aspects, generating mechanisms for transmitting shocks.

The results obtained disprove the notion that the unemployment rate in Uruguay gravitates around an equilibrium level and demonstrate that variables exogenous to the labour market, such as capital accumulation, capital productivity and the working-age population, exert an influence via adjustment processes, generating persistent effects. They also confirm the existence of complementarity in lagged adjustment processes, implying that if these occurred in isolation, over $90 \%$ of the initial impact would disappear in the fourth quarter, whereas if they occur simultaneously, this happens only in the tenth quarter.

The article is organized into four sections after this Introduction. First, the contributions of chain reaction theory are reviewed and the results of its application in other countries presented. After that, the methodology applied in this study is described, following which the results are set forth. Lastly, the conclusions of the study are summarized.

\section{Literature review}

\section{Chain reaction theory: concept and applications}

One of the most influential theories in mainstream macroeconomic studies of unemployment is that there is a natural rate of unemployment or, in the more modern version, a non-accelerating inflation rate of unemployment (NAIRU). Going by evidence on the performance of the labour market in the developed countries over the last three decades of the twentieth century, Layard, Nickell and Jackman (1991) argue for the existence of equilibrium without full employment and identify it as the level of unemployment that does not cause inflation to accelerate. Chain reaction theory arose as an alternative approach to the study of the unemployment rate, dealing with some of the limitations of NAIRU theory: it can be used to model the trajectory of unemployment more comprehensively by combining its short- 
and long-term behaviour, evaluate the effects of variables exogenous to the labour market and explain what factors determine the persistence or permanence of temporary shocks. ${ }^{2}$

Chain reaction theory is based on a multi-equation model of the labour market in which changes in the unemployment rate are seen as "chain reactions" to temporary and permanent shocks in that market.

Unemployment reacts via an interacting network of lagged adjustment processes in the major labour market variables: supply, demand and wages. The behaviour of these variables presents a degree of inertia or memory such that the adjustments are not immediate, implying that their current values depend on their past values, with the result that the effects of shocks on the unemployment rate persist. Process inertia is well documented in the literature on chain reaction theory (Karanassou, Sala and Salvador, 2008) and is due to the presence of labour turnover costs (hiring, training and dismissal) and price and wage staggering, and to the existence of internal markets, unemployment duration effects and adjustments in the labour supply (because of emigration, for example). Another important factor is that the processes are interconnected with one another and with exogenous variables, the result being that external shocks create spillover effects, amplifying their short-run impact on the unemployment rate and extending their duration, while preventing the unemployment rate from converging on an invariant level in the long term (Karanassou and Snower, 1997 and 1998).

Empirically, the study of unemployment from a chain reaction theory perspective is approached by modelling a system of equations like the one presented below: ${ }^{3}$

$$
\begin{gathered}
n_{t}=\alpha_{1} n_{t-1}+\beta_{1} k_{t}-\gamma_{1} w_{t} \\
l_{t}=\alpha_{2} l_{t-1}+\beta_{2} z_{t}+\gamma_{2} w_{t} \\
w_{t}=\beta_{3} x_{t}-\gamma_{3} u_{t}
\end{gathered}
$$

where $n, l$ and $w$ are endogenous variables and represent the demand for labour, the supply of labour and the real wage, respectively. ${ }^{4}$ All the variables in the system except the unemployment rate $(u)$ are expressed in logarithms, so that this rate is obtained from the following expression:

$$
u_{t} \cong l_{t}+n_{t}
$$

The $\alpha_{i}$ coefficients (where $0<\alpha_{i}<1$ ) represent the effects of process inertia, while the $\gamma_{i}$ parameters reflect the interactions between the endogenous variables (spillover effects) ${ }^{5}$ and $\beta_{i}$ show the short-run elasticities of the endogenous variables relative to changes in the exogenous variables, such as the capital stock $(k)$, the working-age population $(z)$ and factors that put pressure on prices $(x)$.

This modelling of chain reaction theory deals with one of the main limitations of the NAIRU approach, which assumes that models of the unemployment rate can only include exogenous variables

2 Chain reaction theory was developed in Karanassou and Snower (1996). For a review, see Karanassou (1998), Karanassou and Snower (1997, 1998 and 2000) and Henry, Karanassou and Snower (2000), among others.

3 The theoretical underpinnings for the specification of each equation are set out in Karanassou and Snower (2000). A summary can be found in Leites and Porras (2013).

4 To simplify, the wage equation excludes the lagged wage effect, following the example of Karanassou, Sala and Snower (2009). Error terms and constants were excluded for the same reason.

5 In this simple version, wages affect the labour supply and demand, while unemployment also affects wage-setting. Higher levels of unemployment will reduce the relative bargaining power of employed workers by making the threat of dismissal credible, which will tend to hold wages down. 
without trend (invariance hypothesis), implying that permanent shocks in exogenous variables lead to compensatory changes in the labour supply and demand curves tending to return unemployment to its original long-run equilibrium rate (Layard, Nickell and Jackman, 1991). A less restrictive kind of modelling (weak invariance hypothesis) includes a stationary linear combination of trend variables that are exogenous to the labour market (Phelps, 1994). Karanassou and Snower (2004) show that these invariance constraints do not apply and that trend variables such as the capital stock, technological change, labour productivity and the working-age population are important in explaining the behaviour of the labour market, and thence unemployment. The requirement is that each endogenous trend variable $(l, n$ and $w$ ) should balance out overall with the explanatory variables.

This approach has been applied to the study of the unemployment rate in the United Kingdom, the United States, Denmark, Australia, Portugal, Spain and a group of countries in the European Union (Karanassou and Snower, 1998; Henry, Karanassou and Snower, 2000; Karanassou, Sala and Snower, 2003; Bande, 2002; Bande and Karanassou, 2009; Karanassou, Sala and Salvador, 2008; Karanassou and Sala, 2008 and 2010; González and Sala, 2011). ${ }^{6}$ These studies highlight the importance of this approach in comparison with a one-equation model of the unemployment rate, concluding that economic policy decisions should not be based on what the natural rate of unemployment determines, since the unemployment rate is found not to gravitate around this equilibrium level.

Inertia in adjustment processes is confirmed in all cases, with only differences in their speed being identified. The demand for labour adjusts more quickly in countries such as Denmark and Australia ( $\alpha_{1}=0.2$ approximately), while at the other extreme is the inertia estimated for the European Union as a whole (0.94), followed by the United States and United Kingdom (about 0.7). It is argued that the finding for Denmark reflects greater flexibility in the country's labour market than in the other countries of the Organization for Economic Cooperation and Development (OECD) in respect of job protection legislation (Karanassou, Sala and Salvador, 2008). Where the labour supply is concerned, the inertia coefficients yielded by the equations are more homogenous and relatively high $\left(\alpha_{2}\right.$ between 0.6 and 0.92), ${ }^{7}$ indicating the existence of workforce entry and exit costs. In all cases, the wage equation also includes lags in the dependent variable. Leaving aside the data for Australia and Denmark, the wage inertia coefficients are also relatively homogeneous and range from 0.55 to 0.83 . As in the case of labour demand, these are the two countries presenting the fastest adjustment processes (0.32 and 0.24, respectively).

Karanassou and Snower (1998) find that over half the changes in the United Kingdom unemployment rate between 1980 and 1995 were due to the medium-run contribution of lagged adjustments in labour market variables. They also indicate that adjustment processes were complementary, creating more substantial effects on the unemployment rate. Henry, Karanassou and Snower (2000) estimate, for the United Kingdom, that a temporary positive shock in labour demand 8 leads to a gradual reduction in the unemployment rate, so that $90 \%$ of the initial effect disappears only after four years. A temporary shock to real wages, meanwhile, leads to a sharp initial increase in the unemployment rate followed by a gradual decline, with $90 \%$ of the total adjustment being completed only after 12 years, while it takes 10 years for $90 \%$ of the adjustment to a labour supply shock to work through.

The real wage was included as an explanatory variable in the labour demand equations for all the countries. The elasticity of long-run employment relative to wage changes takes the expected sign

\footnotetext{
6 The European Union study included the following countries: Austria, Belgium, Denmark, Finland, France, Germany, Italy, the Netherlands, Spain, Sweden and the United Kingdom.

7 There are two different estimates for the United Kingdom, one with an inertia coefficient of 0.45 and the other with a coefficient of 0.75 .

8 They assume a shock entailing an initial change of 1 percentage point in the unemployment rate.
} 
in all the countries, fulfilling the law of demand, ${ }^{9}$ but the values differ in magnitude. This elasticity takes an absolute value of over 0.6 in one of the estimates for Spain, as well as for the United States and Denmark (where it takes values of between 1 and 2). The other estimates indicate a long-run price elasticity of labour demand of less than 0.5 .

Besides the variables mentioned, their lags and their interactions, the equations include other variables exogenous to the labour market as explanatory variables. One of the most-used variables is capital stock, which is included in the labour demand equations. The estimates indicate a positive longrun elasticity ranging from 0.3 to 1.0, implying that there is also a long-run effect on unemployment. In their study of Australia, Karanassou and Sala (2010) conclude that capital accumulation was the factor that most affected the trend of unemployment in the country in the 1990s and early 2000s. On the basis of these findings, the authors question the NAIRU approach and rule out the evolution of unemployment being only a response to temporary shocks or changes in labour market institutions. Karanassou and Sala (2008) find evidence along the same lines for Spain between the 1970s and 2005. They apply chain reaction theory to evaluate the influence of changes in social security contributions, indirect taxes, financial wealth and capital accumulation on the evolution of the unemployment rate in Spain and find capital accumulation to be the factor that does most to explain this.

\section{Studies on unemployment in Uruguay}

Some earlier studies have addressed the issue of unemployment in Uruguay using the most standard approaches as a framework: the natural rate of unemployment approach and the hysteresis hypothesis. What comes out in these studies is, first, that there is no conclusive empirical evidence for the existence of a natural rate of unemployment on which the Uruguayan economy converges, while in other cases they do not reject the presence of a unit root in the country's unemployment series, or at least do not rule out the possibility that temporary shocks may have persistent effects on unemployment.

Borraz and Tubio (2009) reject the existence of a NAIRU in Uruguay in the period from 1978 to 2009, and while they do find a negative relationship between inflation and unemployment, the method used (expectations-augmented Phillips curve) does not allow them to infer causality. ${ }^{10}$ Using a different methodology, though (Kalman filter, univariate modelling), they estimate a "natural" rate of unemployment independent of inflation of $10.64 \%$ for 2009 , implying that the rate actually recorded between 2009 and 2011 was very far below its "natural" level.

Rodríguez (1998) finds evidence for the hysteresis hypothesis when analysing the evolution of the unemployment rate in Montevideo in the period from 1984 to 1996. Similar results are obtained by Badagián and others (2001), who study the dynamics of the capital's quarterly unemployment rate in the period from the fourth quarter of 1983 to the second quarter of 2001, concluding that unemployment has the behaviour of a long-memory stochastic process (even assuming structural breaks), which would be inconsistent with the existence of a stationary natural rate of unemployment. Another study, also on the Montevideo unemployment rate, in this case during 1968-1997, concludes that the effects of temporary shocks tend to disappear but are highly persistent (Spremolla, 2001).

This evidence implies a degree of inertia in the behaviour of the unemployment rate, which could be explained by long-memory processes in the major labour market variables, such as demand, supply and wage formation. This would imply that there were certain rigidities in the labour market, and that there were no automatic adjustments.

\footnotetext{
9 In the study by Karanassou and Snower (1998) on the United Kingdom, this elasticity presents with a positive sign, but the document does not make any comment on this.

10 In the authors' judgement, processes driven by independent structural variables are what determine both inflation and unemployment.
} 
The evidence available so far is generally inconclusive. The recent dynamism of the Uruguayan labour market raises the question of what factors might have been determining the low levels of unemployment seen in recent years. Weller (2014) argues that the recent evolution of unemployment in the countries of Latin America and the Caribbean is explained by a favourable production environment (economic growth, rising productivity and the behaviour of other production factors) and by institutional aspects. Approaching this issue via chain reaction theory will provide direct evidence on the importance of factor productivity and capital accumulation in explaining unemployment. It will also provide indirect evidence for the way institutional factors and the production context interact to amplify the effects of shocks.

\section{Methodology}

A multi-equation dynamic model is estimated in order to explain the evolution of unemployment in Uruguay, taking the chain reaction theory approach as a starting point. Karanassou and Snower (2000) developed the theoretical underpinnings for the modelling of each of the equations in the system.

The labour demand equation is configured to derive this demand from that for final goods and services on the basis of profit maximization for firms operating in non-competitive markets in the presence of adjustment costs. In this framework, demand for labour depends, first, on its own past (lagged dependent variable), which indicates the existence of inertia, owing to the adjustment costs faced by employers in hiring or dismissing workers. For labour demand to be dynamically stable, the coefficient of inertia must be less than 1. Furthermore, the value of this coefficient reflects the speed with which the demand for labour adjusts to external shocks: the closer to 1 the coefficient is, the slower the adjustment will be, and the closer to 0 the coefficient, the quicker the adjustment. The demand for labour also depends on its own price (real wage), the capital stock and capital productivity.

The labour supply equation includes at least one lag of the dependent variable, on the assumption that there are workforce entry and exit costs. This is conducive to inertia in labour supply decisions. Furthermore, changes in supply also depend on other factors: (i) the growth of the working-age population; (ii) real wages, without a predetermined sign, given that supply can react to pay increases positively (substitution effect) or negatively (income effect), and (iii) the unemployment rate, whose effect could be negative insofar as the discouraged worker effect operates (part of the labour force gives up the search for work because of a lack of opportunities) or positive if the added worker effect predominates (more people enter the market in response to an increase in the number of unemployed in their household, in order to make up for the lost income).

Lastly, the wage equation contains at least one lag of the dependent variable, associated with the inertia that is explained by the wage staggering effect. This derives from bargaining between workers and firms, who agree on pay increases in the light of the past trajectory, so that the influence of the lags is immediate. According to Bande (2002), the descriptive model of aggregate wage behaviour is based theoretically on the wage staggering processes described by Taylor (1979). It is assumed that contracts are valid for one period but are determined at two points in time, half at the beginning of the year and the other half in the middle of the period. The result is that the current wage depends on the previous period's wage. ${ }^{11}$ Furthermore, wages depend on pay bargaining capacity, which can be modelled as a function of the unemployment level. The size of this variable is believed to capture the insider membership effect on pay bargaining capacity, the idea being that an "insider" group of labour market participants have a privileged position relative to outsiders, explained essentially by the

\footnotetext{
11 Developed in Bande (2002).
} 
cost to firms of staff turnover. ${ }^{12}$ Higher unemployment would reduce the bargaining power of insiders and exert downward pressure on wages, while the opposite would happen if unemployment were low. The more traditional theory also includes changes in labour productivity as an explanatory factor in wage movements. ${ }^{13}$

On these foundations, the following system is estimated:

$$
\begin{gathered}
n_{t}=c_{n}+\alpha_{n} n_{t-1}+\gamma_{1} w_{t}+\beta_{1} k_{t}+\beta_{2} p r k_{t}+\varepsilon_{n} \\
l_{t}=c_{l}+\alpha_{l} l_{t-1}+\gamma_{2} w_{t}+\gamma_{3} u_{t}+\beta_{3} z_{t}+\varepsilon_{l} \\
w_{t}=c_{w}+\alpha_{w} w_{t-1}+\gamma_{4} u_{t}+\beta_{4} p r n_{t}+\varepsilon_{w}
\end{gathered}
$$

Where:

$$
u_{t}=l_{t}-n_{t}
$$

where $n_{t}$ is the number of people in work, $w_{t}$ the average real wage, $k_{t}$ the capital stock, $p r k_{t}$ apparent capital productivity, $l_{t}$ the number of people active in the labour market, $u_{t}$ the unemployment rate, $z_{t}$ the working-age population and $\operatorname{prn}_{t}$ apparent labour productivity. All the variables other than the unemployment rate are expressed in logarithms, so that the estimated coefficients for each explanatory variable represent the short-run elasticity of the dependent variable relative to changes in these variables. Furthermore, $c_{i}$ and $\varepsilon_{i}$ (with $i=n, l$ and $w$ ) represent the constant and the error term of each equation, respectively.

The next step after estimating the system is to contrast the following hypotheses:

- Ha. The presence of an inertia effect. This is considered by analysing the significance of the lagged endogenous variables in each equation. In terms of the model specified, the presence of the inertia effect implies rejection of Ha: $\alpha_{n}=0 ; \alpha_{l}=0 ; \alpha_{w}=0$.

- $\quad \mathrm{Hb}$. The influence of variables exogenous to the labour market. The significance of the following variables is evaluated: the capital stock, capital productivity, the working-age population and labour productivity. Trend variables exogenous to the labour market can be said to affect the unemployment rate if one or more of the following hypotheses hold true: $\beta_{1} \neq 0 ; \beta_{2} \neq 0$; $\beta_{3} \neq 0 ; \beta_{4} \neq 0$.

- Hc. Spillover effects. Within the framework of the model specified, there are found to be spillover effects if one or more of the following hypotheses hold true: $\gamma_{1} \neq 0 ; \gamma_{2} \neq 0 ; \gamma_{3} \neq 0 ; \gamma_{4} \neq 0$. This would imply that there was interaction between the equations, so that a shock found to affect one of the endogenous variables will create spillover effects on the others, which could result in the unemployment adjustment process being even more prolonged.

The above hypotheses were contrasted by evaluating the statistical significance of the coefficients estimated in each equation. According to chain reaction theory, non-rejection of hypotheses $\mathrm{Ha}$ and $\mathrm{Hc}$ implies that temporary shocks will have a persistent effect on the unemployment rate. Simulation techniques based on impulse-response functions were used to evaluate this persistence.

- $\quad H d$. Hypothesis of complementarity in lagged adjustment processes. Another of the aspects flagged up in the literature on the subject is that the effects on unemployment can be amplified

\footnotetext{
12 Montuenga and Ramos (2005) propose different justifications for bringing in the unemployment rate as a determinant of wages.

${ }^{13}$ Efficiency wage models suggest that labour productivity could be endogenous to the system, an aspect that has not hitherto been considered in chain reaction theory.
} 
and/or prolonged when there is complementarity in adjustment processes. As a way of contrasting this hypothesis in the case of Uruguay, we follow Henry, Karanassou and Snower (2000) and use simulation techniques to compare the effects of a shock on unemployment in the following two simulations: one in which all the effects are considered to operate simultaneously, and one that consists in adding up the individual influences of each equation as though they operated separately.

Lastly, a secondary objective is to investigate the determinants of the recent drop in unemployment in Uruguay, exploring how important capital accumulation has been for the unemployment dynamics of the past few years. For this, following Karanassou and Snower (1998), a simulation exercise is carried out in order to identify the factors contributing most to the drop in unemployment between 2003 and 2011.

We estimated the equations using autoregressive modelling with distributed lags of order $p$ and $q$, analysing the cointegration of the variables included in the modelling with the methodology proposed in the studies by Pesaran and Shin (1995), Pesaran, Shin and Smith (1996 and 2001), and Pesaran (1997), with $p$ and $q$ corresponding to the order of lags of the dependent variable and the independent variable, respectively.

This methodology is the one used in the earlier literature applying the chain reaction theory approach, as it presents certain advantages over the cointegration techniques normally employed to estimate long-term relationships and short-term adjustment mechanisms. In the first place, it is useful for evaluating the significance of the coefficients of the lags of the endogenous variables, which has a clear economic interpretation in the chain reaction theory framework. Second, this approach does not require a priori knowledge of the order of integration of the variables to analyse long-term relationships, which means that the problems involved in identifying unit roots do not have to be dealt with. Also avoided as a result are the problems associated with the application of traditional cointegration methods, which require long series.

Since the lagged dependent variable is included in the modelling of each equation, estimating the system by ordinary least squares (OLS) could present problems of endogeneity and correlation with residuals. To mitigate these problems, instrumental variables are employed and the model is estimated using the three-stage least squares (3SLS) procedure.

Quarterly series were used for the period between the first quarter of 1985 and the fourth quarter of 2011 (see table A1.1 of the annex). The labour market information used was arrived at by processing microdata from the continuous household surveys of the National Institute of Statistics (INE) and is representative of the urban population of Uruguay (settlements of 5,000 inhabitants and over). ${ }^{14}$ The series for the working-age urban population was constructed from the urban population projections of INE and the Latin American and Caribbean Demographic Centre (CELADE)-Population Division of the Economic Commission for Latin America and the Caribbean (ECLAC). The real wage series comes from INE wage statistics. The capital stock series was constructed by turning an annual series available in Román and Willebald (2012) into a quarterly one using a constant depreciation rate and quarterly investment information from the national accounts of the Central Bank of Uruguay.

Two apparent productivity series were constructed to gain an idea of the evolution of capital and labour productivity. The first was obtained from the ratio between gross domestic product (GDP) as reported by the central bank and the capital stock. This is a proxy for apparent capital productivity, since the ratio incorporates capital stock rather than capital use, which would be the correct choice. Apparent labour productivity was constructed from the ratio between GDP and total hours worked, a figure obtained by processing the continuous household surveys.

14 This information is used because the survey was extended to smaller settlements and rural areas only in 2006. 


\section{Results}

\section{Estimating the system of equations}

The econometric methodology applied first requires the F-test to be contrasted with the three equations making up the multi-equation dynamic model: labour demand, labour supply and wages. This test evaluates the null hypothesis $\left(H_{0}\right)$; namely, that there is no cointegration between the variables. In all three cases, the F-statistic was above the critical value in the tables given by Pesaran, Shin and Smith (2001), so that it was possible to reject $\mathrm{H}_{0}$ and conclude that there was a long-term relationship between the variables included in each model (see table A1.2 of the annex).

With the existence of a long-term relationship confirmed, the multi-equation dynamic model was estimated. The results discussed below are those obtained by estimating the system of equations using the 3SLS method (see table 1)..$^{15}$

Table 1

Estimation of labour market equations by the three-stage least squares (3SLS) method ${ }^{a}$

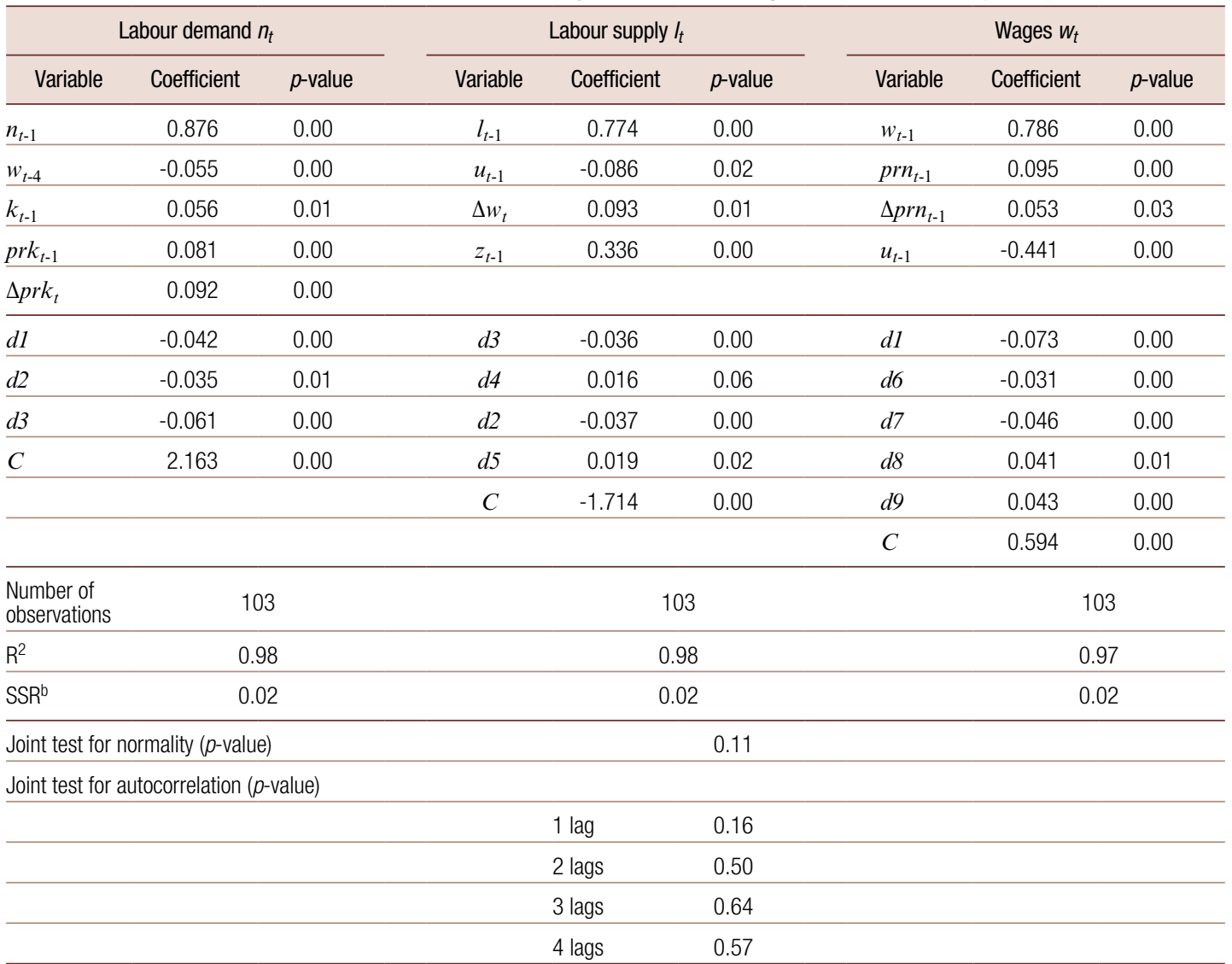

Source: Prepared by the authors.

a Instrumental variables: $n_{t-1}, l_{t-1}, w_{t-1}, w_{t-4}, w_{t-5}, k_{t-1}, k_{t-2}, p r k_{t-1}, p r k_{t-2}, \Delta p r k_{t}, \Delta p r k_{t-1}, u_{t-1}, u_{t-2}, u_{t-3}, u_{t-4}, \Delta w_{t}, \Delta w_{t-1}, \Delta w_{t-2}, z_{t-1}, z_{t-2}$, $z_{t-3}, \operatorname{prn}_{t-1}, \operatorname{prn}_{t-2}, \Delta \operatorname{prn}_{t-1}, \Delta p r n_{t-2}, d 1, d 2, d 3, d 4, d 5, d 6, d 7, d 8, d 9$ and $c$.

b Sum of squared errors.

15 The results obtained with the 3SLS method do not differ substantially from those produced when the system is estimated by OLS. See table A1.5 of the annex in Leites and Porras (2013). 
The estimated coefficients of the variables included in the three equations of the system proved to be significant, with the expected signs; in addition, their residuals are well behaved (normal, without autocorrelation or heteroskedasticity), both in the estimation of the system and in the estimation of each equation separately (see table A1.3 of the annex).

The results indicate that the demand for labour depends, in the first place, on its own past $\left(n_{t-1}\right)$, which confirms the existence of inertia due to the adjustment costs to employers of hiring or dismissing workers, such as the cost associated with training up new employees. The estimation yields a labour demand inertia coefficient of 0.876, a fairly high level by the standards of the estimates for other countries that were mentioned earlier, indicating that labour demand shocks will have effects on the unemployment rate that will not quickly disappear.

In addition, as was to be expected, the demand for labour relates negatively to its price (the real wage), but this relationship does not link the two elements simultaneously, as movements in the real wage impact labour demand only after a four-quarter lag. According to the coefficient estimated, an increase of $1 \%$ in real wages reduces long-run labour demand by $0.45 \%$ [ $=-0.055 /(1-0.876)]$. It should be noted that the real wage variable refers to the cost of employees, so that presumably the elasticity estimated would be greater if the universe of demand were restricted to workers of this type.

As in other countries, the capital stock in Uruguay explains labour demand, in this case with one lag. A rise of $1 \%$ in the capital stock generates a total rise of $0.45 \%$ [ $=0.056 /(1-0.876)]$ in labour demand. This elasticity is close to the values estimated for a number of the countries, as already discussed. Not only did the capital stock prove significant in explaining shifts in labour demand, but so did capital productivity, in level and variation. The long-run elasticity of labour demand relative to the level of capital productivity was estimated at 0.65 , while the long-run elasticity of that demand relative to the variation in capital productivity was estimated at 0.74 .

The estimated inertia coefficient in the labour supply equation $(0.774)$ is rather lower than the one for labour demand, but within the range of values estimated for the other countries. As with the countries where the unemployment rate was included as an explanatory factor for supply, the sign of the elasticity indicates that the discouraged worker effect also operates in Uruguay. What this means is that an increase of 1 percentage point in the unemployment rate translates into a drop of $0.38 \%$ in the labour supply $[=-0.086 /(1-0.774)],{ }^{16}$ indicating a widespread belief among people seeking work in this context that it is going to be difficult to find, so that a proportion of them abandon the search and drop out of the market. At the same time, the labour supply reacts positively $(0.41 \%)[=0.093 /$ $(1-0.774)]$ to a $1 \%$ rise in the real wage, indicating that the substitution effect prevails over the income effect, i.e., that when wages increase, so does the number of people preferring to substitute work for leisure. Lastly, as would be expected, the working-age population is the exogenous variable that does most to explain the evolution of the labour supply. Thus, an increase of $1 \%$ in this variable leads to a rise of $1.49 \%$ in the supply [ $=0.336 /(1-0.774)]$, indicating an elasticity that is around the average of the values estimated for developed countries.

The significance of the lagged dependent variable in the wage equation shows that real wages also evince a degree of inertia (0.786) associated with the wage staggering effect. The size of this coefficient is close to the values estimated for most developed countries, which indicates in this case too that wage shocks will have effects on the unemployment rate that do not disappear quickly. For its part, the coefficient for the unemployment rate that was included in this equation could be capturing a degree of flexibility in the response of real wages to labour market conditions, in the sense that employed workers lose wage bargaining power when unemployment is rising, which places downward pressure on real wages. Thus, a rise of 1 percentage point in the unemployment rate leads to a long-

16 The dependent variable is logarithmic, whereas the unemployment variable is a rate, so that the estimated coefficient multiplied by 100 is interpreted as the semi-elasticity of the labour supply relative to the unemployment rate. 
term reduction of $2.06 \%$ in real wages. Although having the same sign, this elasticity is slightly above the values (ranging from $0.5 \%$ to $1.5 \%$ ) estimated for the other countries whose supply equations included this variable as an explanatory factor for real wages. Wages also respond to changes in the levels and variation of labour productivity per hour worked. The long-run elasticity of wages was estimated at 0.44 (total effect) relative to labour productivity levels and 0.25 relative to variation. These values are below those found for the United States in 2011 using a comparable specification (1.0 and 3.29 , respectively).

Dummy variables also had to be included in all three equations, usually because of outlying oneoff values in the series or events in the Uruguayan economy that produced some break in the series, such as the 2002 crisis (see table A1.1 of the annex).

The system estimated yields a satisfactory prediction of the evolution of the unemployment rate in Uruguay over the last 27 years. This can be seen in figure 2, which presents the actual evolution of the unemployment rate $\left(l_{t}-n_{t}\right)$ and the evolution estimated from the system of equations (with and without dynamic interaction). ${ }^{17}$

Figure 2

Evolution of the actual unemployment rate and the rate estimated from the system of equations, 1985-2011

(Percentages)

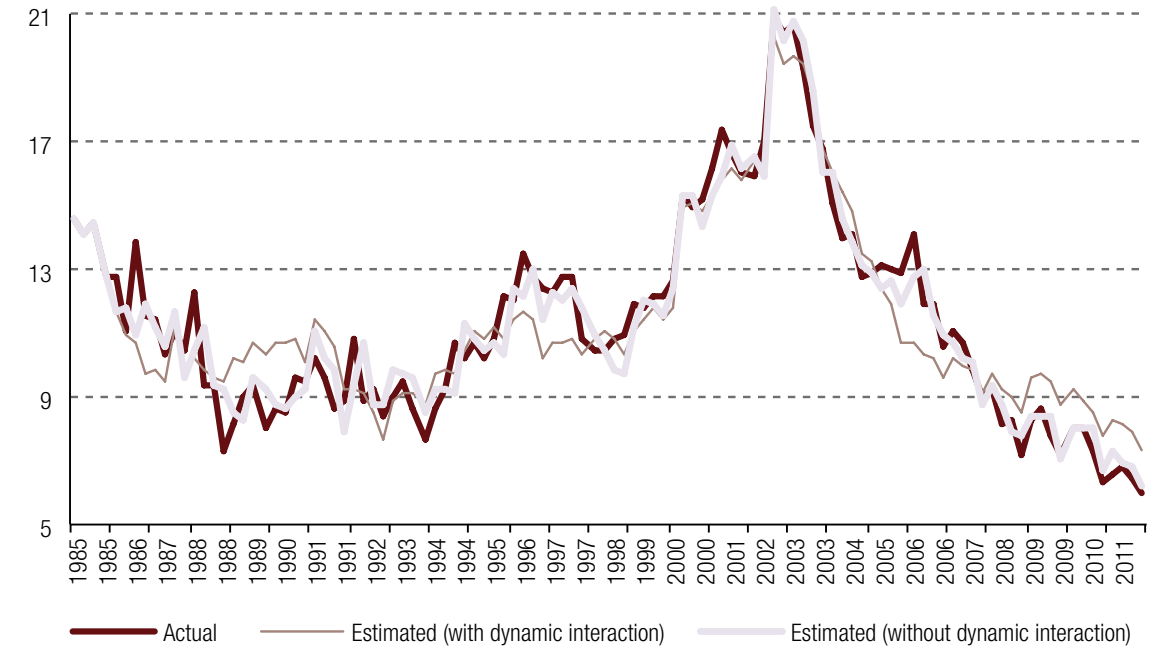

Source: Prepared by the authors.

\section{Hypothesis testing and implications}

The results of the estimates provide a response to the first three questions raised. Table 2 presents the hypotheses and the statistical tests and summarizes their results. In the first place, all three equations confirm the significance of the lagged dependent variables $\left(\alpha_{i} \neq 0\right)$, which is evidence for inertia in labour market adjustment processes ( $\mathrm{Ha})$. In the second place, it is found that the capital stock and capital productivity have a significant effect on labour demand, that the working-age population affects the labour supply and that labour productivity affects wages, confirming the influence of exogenous variables on the unemployment rate $\left(\beta_{i} \neq 0, \mathrm{Hb}\right)$. Lastly, wages are important in explaining labour

\footnotetext{
17 The inclusion of dynamic interaction means that the unemployment rate estimated by the system is then incorporated into successive estimates of labour supply and wages. The projection that does not incorporate dynamic interaction takes the actual unemployment rate as an explanatory variable for supply and wages.
} 
supply and demand, and unemployment is important in explaining both wages and the labour supply, thus confirming the significance of interactions between the equations and the presence of spillover effects $\left(\gamma_{i} \neq 0, \mathrm{Hc}\right)$.

Table 2

Hypothesis testinga

\begin{tabular}{|c|c|c|c|c|c|}
\hline \multirow{2}{*}{ Hypothesis } & & \multicolumn{3}{|c|}{ Equations $^{b}$} & \multirow{2}{*}{ Conclusion } \\
\hline & & Demand & Supply & Wages & \\
\hline \multirow{2}{*}{$\begin{array}{l}\text { Ha: presence of inertia effect } \\
\text { HO: coefficient }=0 \mathrm{H} 1 \text { : coefficient } \neq 0\end{array}$} & Estimated coefficient & $\alpha_{n}=0.876$ & $\alpha_{l}=0.774$ & $\alpha_{w}=0.786$ & \multirow{2}{*}{$\begin{array}{l}\text { Presence of inertia } \\
\text { not rejected }\end{array}$} \\
\hline & t-test ( $p$-value) & 0.00 & 0.00 & 0.00 & \\
\hline \multirow{6}{*}{$\begin{array}{l}\text { Hb: influence of exogenous variables } \\
\text { H0: coefficient }=0 \mathrm{H} 1 \text { : coefficient } \neq 0\end{array}$} & Estimated coefficient & $\beta_{1}=0.056$ & $\beta_{4}=0.336$ & & \multirow{6}{*}{$\begin{array}{l}\text { Influence of exogenous } \\
\text { variables not rejected }\end{array}$} \\
\hline & t-test ( $p$-value) & 0.01 & 0.00 & & \\
\hline & Estimated coefficient & $\beta_{2}=0.081$ & & & \\
\hline & t-test ( $p$-value) & 0.00 & & & \\
\hline & Estimated coefficient & $\beta_{3}=0.092$ & & & \\
\hline & t-test ( $p$-value) & 0.00 & & & \\
\hline \multirow{4}{*}{$\begin{array}{l}\text { Hc: presence of spillover effects } \\
\text { HO: coefficient }=0 \mathrm{H} 1 \text { : coefficient } \neq 0\end{array}$} & Estimated coefficient & $\gamma_{1}=-0.055$ & $\gamma_{2}=-0.086$ & $\gamma_{4}=-0.441$ & \multirow{4}{*}{$\begin{array}{l}\text { Presence of spillover } \\
\text { effects not rejected }\end{array}$} \\
\hline & t-test ( $p$-value) & 0.00 & 0.02 & 0.00 & \\
\hline & Estimated coefficient & & $\gamma_{3}=0.093$ & & \\
\hline & t-test ( $p$-value) & & 0.01 & & \\
\hline
\end{tabular}

Source: Prepared by the authors.

a Contrasts of hypotheses based on the results of the estimations of the system equations presented in table 1.

b The equations are as follows:

Demand: $n_{t}=\alpha_{n} n_{t-1}+\beta_{1} k_{t-1}+\beta_{2} p r k_{t-1}+\beta_{3} \Delta p r k_{t}+\gamma_{1} w_{t-4}$

Supply: $l_{t}=\alpha_{l} l_{t-1}+\beta_{4} z_{t-1}+\gamma_{2} u_{t-1}+\gamma_{3} \Delta w_{t}$

Wages: $w_{t}=\alpha_{w} w_{t-1}+\beta_{5}$ prn $_{t-1}+\beta_{6} \Delta p r n_{t}+\gamma_{4} u_{t-1}$

Where:

$n$ : Number of people in work; $w$ : Average real wage; $k$ : Capital stock; prk: Apparent productivity of capital; l: Number of people active in the labour market; $u$ : Unemployment rate; $z$ : Working-age population; prn: Apparent productivity of labour.

The confirmation of these three hypotheses suggests that a temporary shock to any of the labour market variables can generate a persistent effect on the level of unemployment. To evaluate the magnitude of these effects, exercises were first carried out to simulate demand, supply and wage shocks. This made it possible to measure the persistence in time of their effects on the unemployment rate. Second, shocks in variables exogenous to the labour market were simulated. Lastly, this was followed by an evaluation of lagged adjustment processes to ascertain whether they were complementary and amplified their effects (hypothesis $\mathrm{Hd}$ ).

\section{(a) Demand, supply and wage shocks}

Two types of shocks to the labour demand, wage-setting and labour supply equations were simulated: a one-off shock and an autoregressive shock of type $\operatorname{AR}(1)$ with $\rho=0.5$. The effects of the shocks were normalized so that the initial impact on the unemployment rate would be 1 percentage point.

As can be seen in figures $3 \mathrm{~A}$ and $3 \mathrm{~B}$, shocks generate different dynamics for unemployment depending on whether they originate from demand, supply or wages. One-off demand and supply 
shocks lead to an increase in unemployment, ${ }^{18}$ with effects that persist for 11 and 8 quarters, respectively. The effects of the shock diminish by over $90 \%$ by the end of the ninth quarter in the first case and the sixth quarter in the second. Wage shocks have a less substantial immediate effect, but their effect on unemployment becomes more significant after a year, as higher wages negatively affect the demand for labour with a lag of four quarters, and the effects persist for over five years.

Figure 3

Trajectory of unemployment in response to labour demand, labour supply and wage shocks (Percentage points)

A. One-off shock

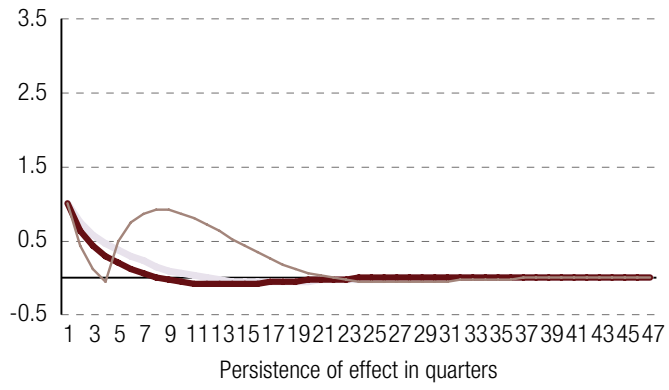

Demand shock
B. Shock of type AR(1) with $\rho=0.5$

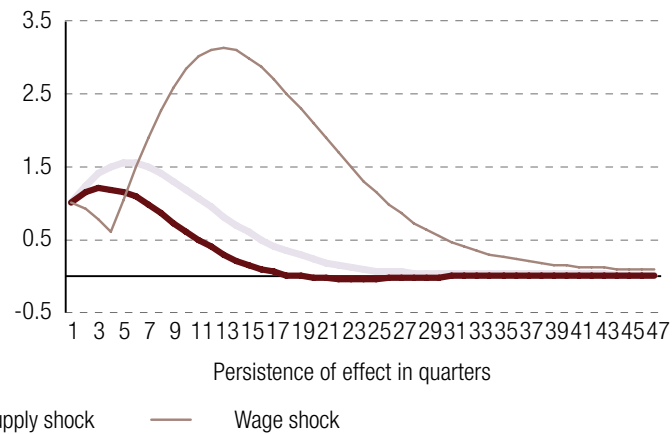

Source: Prepared by the authors.

In response to $\mathrm{AR}(1)$ shocks, unemployment overshoots and is highly persistent in the long run (the effects take roughly 5 to 13 years to disappear). When it comes to wages, unemployment overshoots more, rising practically without check until well into the third year, followed by effects that disappear only very slowly. Once again, it was in the study on the United Kingdom that the effects of wage shocks on unemployment were found to be most persistent relative to those of demand or supply shocks (Henry, Karanassou and Snower, 2000).

\section{(b) Shocks to exogenous variables}

This exercise illustrates how the interaction of exogenous variables along with delayed adjustments generates persistent effects on the long-run unemployment rate.

Three types of shocks were simulated for each exogenous variable: a one-off shock (without memory) and two AR(1) shocks, with $\rho=0.5$ and $\rho=0.9$. In all cases, the effects were normalized so that the initial impact on unemployment was a change of 1 percentage point in the rate. The results are presented in figures $4 \mathrm{~A}$ to $4 \mathrm{D}$.

In the case of shocks to the capital stock, capital productivity and the working-age population, unemployment is found to follow a similar trajectory. With a one-off shock, unemployment reacts and then gradually returns to its starting level; when the shock has memory, however, unemployment initially overshoots, with the initial effect sometimes being more than doubled before it very slowly dissipates. When a shock derives from the capital stock, the effects can be seen to persist for up 10 quarters in the case of a one-off shock and up to 25 in the case of one with lags.

18 What is assumed in this case is a negative labour demand shock leading to increased unemployment. 
Figure 4

Effects on the unemployment rate of shocks to exogenous variables

(Percentage points)

A. Capital stock

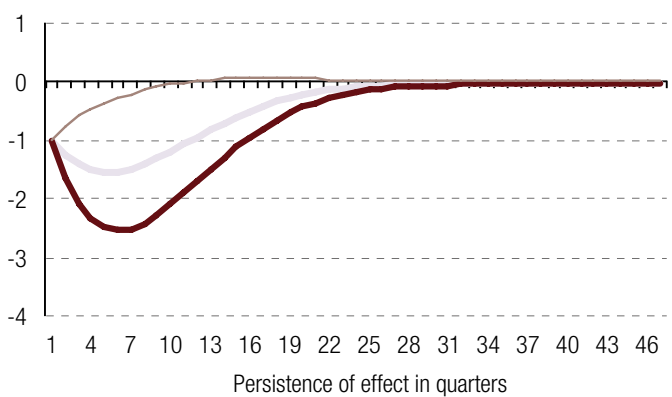

C. Working-age population

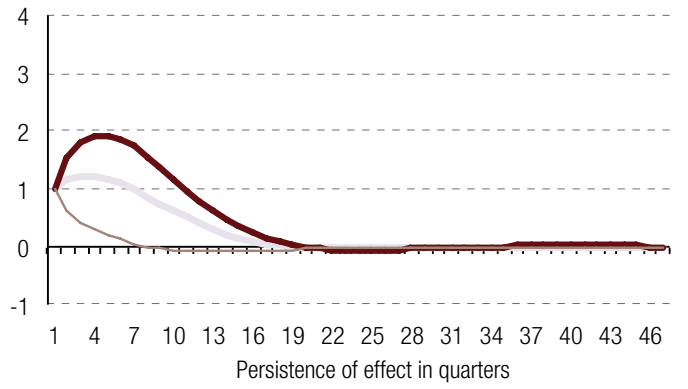

- One-off shock
B. Capital productivity

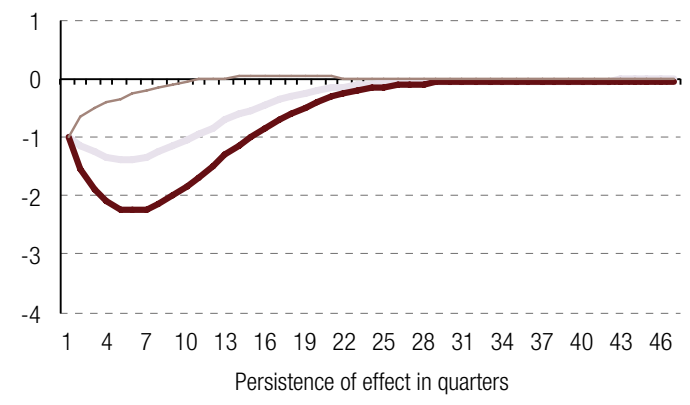

D. Labour productivity

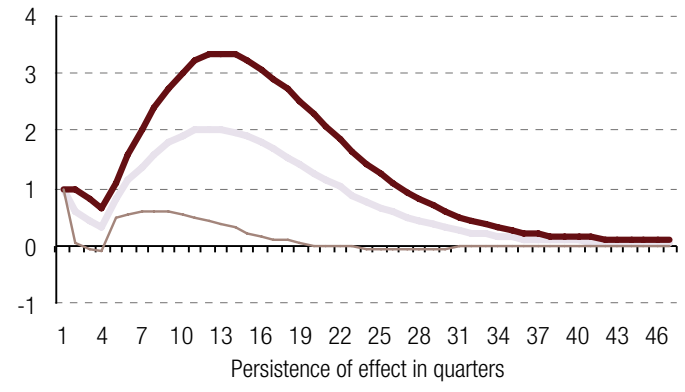

- AR(1) shock with $\rho=0.9$

Source: Prepared by the authors.

The effects of labour productivity shocks on unemployment do not present such a gradual trajectory as in the previous cases, as there is first an immediate drop in unemployment and then an overshoot due to the demand effects of the lagged wage. The effect on unemployment is much greater in subsequent periods than initially, peaking at 3.34 percentage points, and is also more persistent (it only disappears after a period that may range from 5 to 17 years, depending on the type of shock).

\section{(c) Process complementarity}

To gauge the magnitude of the complementarities in the adjustment processes empirically, we follow Henry, Karanassou and Snower (2000). A labour demand shock is assumed and the results of the following two simulations are compared: one assuming that all the effects operate simultaneously, and one arrived at by adding up the individual contributions of each equation.

To derive the individual contribution of the demand equation to the unemployment adjustment process, all the endogenous variables of the system are first fixed at their current value, with the exception of the employment lag in the demand equation. In this way, the shock simulation will only encompass the effect on the unemployment rate of inertia in the demand for labour itself. Next, the individual contribution of the supply equation in the face of this demand shock is obtained, this time by fixing all the endogenous variables at their current value except the one for the supply lag. The same procedure is followed to obtain the individual contribution of the wage equation. 
In the next step, the individual responses are added together and normalization is carried out so that the immediate effect of the shock on unemployment is 1 percentage point. This yields a series for the effect of a demand shock on unemployment when the adjustment processes act in isolation.

Figure 5 shows that a demand shock has an amplified effect on unemployment when adjustment processes are complementary, and that this takes longer to disappear, providing evidence for hypothesis $\mathrm{Hd}$. In the case of a one-off shock, the effects disappear only after 11 quarters, whereas if adjustment processes did not complement one another their effects would disappear in less than half the time. If the shock additionally follows an $\mathrm{AR}(1)$ process with $\rho=0.5$, complementarity means not only that its effects are longer-lasting, but that they are amplified, even resulting in an overshoot.

Figure 5

Complementarity of lagged adjustment processes: individual and joint effects of a labour demand shock on the unemployment ratea

(Percentage points)

A. One-off shock

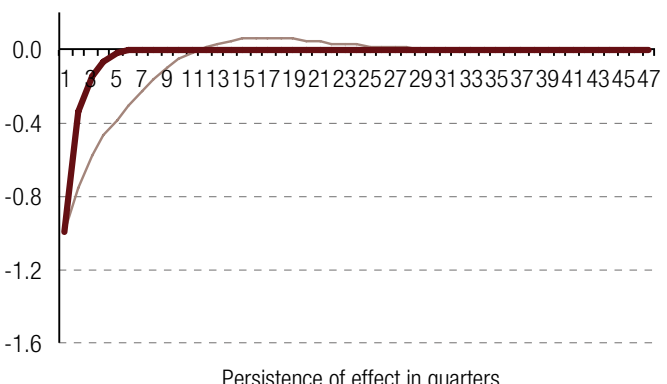

Persistence of effect in quarters
B. $A R(1)$ shock with $\rho=0.5$

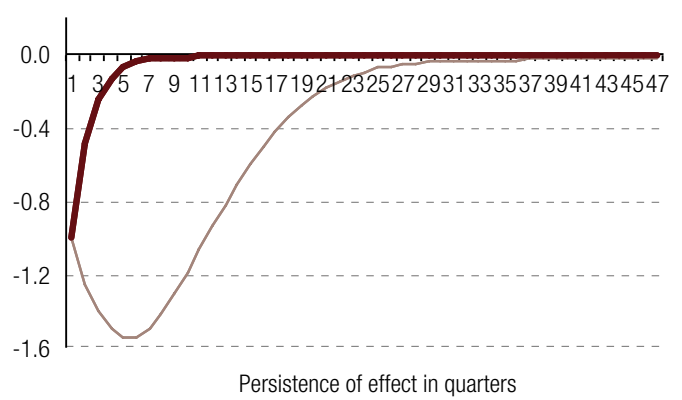

Sum of individual effects

Source: Prepared by the authors.

a The effects are calculated by means of two simulations: one assuming that they all operate simultaneously and including their interactions (joint effect), and one arrived at by adding up the individual contributions of the demand, supply and wage equations to the unemployment adjustment process.

\section{Determinants of the recent evolution of unemployment}

Lastly, an objective of this article was to attempt to ascertain which factors accounted for the drop in the Uruguayan unemployment rate from the high levels of the 2002 crisis to the historically low figures of recent years. To this end, the analysis concentrated on the period from the first quarter of 2003 to the fourth quarter of 2011. It first distinguished the changes in the unemployment rate over the period, analysing the contribution of inertia in adjustment processes. Secondly, it considered what contribution had been made by the complementarity of adjustment processes. Lastly, it explored the influence of exogenous variables on the trajectory of unemployment during the period.

Following Karanassou and Snower (1998), we estimated the contribution of inertia processes to the drop in the unemployment rate $\left(\Delta \mathrm{u}^{\wedge} 2011-2003\right)$. For this, we first calculated the total change in the unemployment rate between 2003 and 2011, using the full system of equations $\left(\Delta \mathrm{u}_{2011-2003}\right)$. The result was that, with all the adjustments in place, the unemployment rate dropped by 10.69 percentage points in the period. We then calculated this same change, but under the assumption that the lagged adjustments of the endogenous variables did not operate in the system $\left(\Delta u^{n}{ }_{2011-2003}\right)$. These variables were assumed to stand at their current level, meaning that the adjustment process was completed in each period. This procedure yielded a 5.62 percentage point drop in the rate and made it possible to measure what the change in unemployment would have been if the changes in the exogenous variables alone had operated. The difference between the two movements yields the 
contribution of the inertia and the interactions, accounting in this case for almost half the drop in the unemployment rate $\left(\Delta \mathrm{u}_{2011-2003}=\Delta \mathrm{u}_{2011-2003}-\Delta \mathrm{u}_{2011-2003}=5.07\right.$ percentage points) (see table 3), with the rest being accounted for by the effects of the exogenous variables.

Table 3

Contribution of lagged adjustments to the change in the unemployment rate between 2003 and 2011

(Percentage points)

\begin{tabular}{|c|c|c|c|c|}
\hline & & & & $\begin{array}{c}\text { Change in the } \\
\text { unemployment rate }\end{array}$ \\
\hline Total & & $\Delta \mathrm{u}_{2011-2003}$ & $=$ & -10.69 \\
\hline Without lagged adjustments in endogenous variables & & $\Delta \mathrm{u}_{2011-2003}$ & $=$ & -5.62 \\
\hline Joint contribution of lagged adjustments & & $\Delta u_{2011-2003}^{\wedge}$ & $=$ & -5.07 \\
\hline With demand inertia only & & $\Delta u(E A)_{2011-2003}$ & $=$ & -6.25 \\
\hline With wage inertia only & & $\Delta \mathrm{u}(\mathrm{WF})_{2011-2003}$ & $=$ & -5.61 \\
\hline With supply inertia only & & $\Delta \mathrm{u}(\mathrm{LF})_{2011-2003}$ & $=$ & -4.93 \\
\hline \multicolumn{5}{|l|}{ Individual inertia contributions } \\
\hline & $\Delta u^{\wedge}(E A)_{2011-2003}=\Delta u(E A)_{2011-2003}$ & $-\Delta u_{2011-2003}^{n}$ & $=$ & -0.63 \\
\hline & $\Delta u^{\wedge}(W F)_{2011-2003}=\Delta u(W F)_{2011-2003}$ & $-\Delta u_{2011-2003}^{n}$ & $=$ & 0.01 \\
\hline & $\Delta \mathrm{u}^{\wedge}(\mathrm{LF})_{2011-2003}=\Delta \mathrm{u}(\mathrm{LF})_{2011-2003}$ & $-\Delta u_{2011-2003}^{n}$ & $=$ & 0.69 \\
\hline \multicolumn{5}{|l|}{ Joint contribution of individual effects } \\
\hline & $\Delta u^{\wedge}(E A)_{2011-2003}+\Delta u^{\wedge}(W F)_{2011-20}$ & $03+\Delta u^{\wedge}(L F)_{2011-2003}$ & $=$ & 0.07 \\
\hline
\end{tabular}

Source: Prepared by the authors.

Note: $\quad \Delta u$ :Change in projected unemployment; $\Delta u^{n}$ : Change in unemployment without inertia; $\Delta u^{\wedge}$ : Change in unemployment due to inertia; EA: Demand inertia; LF: Supply inertia; WF: Wage inertia.

To measure the importance of the complementarity of lagged adjustment effects, a simulation was made of the change in the unemployment rate between those years under the assumption that this complementarity does not exist. To estimate the change without adjustment complementarity, the contributions of the individual inertia of each variable are added together. In the case of labour demand $\left(\Delta u^{\wedge}(E A)_{2011-2003}\right)$, for example, the individual contribution of inertia is given by the difference between the change in the unemployment rate assuming demand inertia only $\left(\triangle \mathrm{u}(\mathrm{EA})_{2011-2003}\right)$ and the change in the unemployment rate without any inertia process $\left(\Delta u^{n}{ }_{2011-2003}\right)$. Similarly, the contribution of inertia in the labour supply $\left(\Delta u^{\wedge}(L F)_{2011-2003}\right)$ and in wages $\left(\Delta u^{\wedge}(W F)_{2011-2003}\right)$ is estimated. As can be seen in table 3 , the unemployment rate would have risen by 0.07 percentage points instead of dropping by 5.07 percentage points as described above. It can be observed that the drop in the unemployment rate attributable to demand inertia between 2003 and 2011 was 0.63 percentage points, while that attributable to supply inertia was 0.69 , but the contribution of wages was almost nil.

Lastly, what would have happened to the unemployment rate if the exogenous variables had not registered changes between 2003 and 2011? The capital stock and capital productivity, the workingage population and labour productivity all rose between those years. The exercise is to simulate the trajectory of unemployment by altering the value of the exogenous variables.

As a reference, we considered the series for the unemployment rate produced by estimating the full system of equations. After this, the contribution of the capital stock to the evolution of the unemployment rate was calculated by simulating the trajectory of unemployment on the assumption that the capital stock in each quarter of the period from 2004 to 2011 was at the same level as in the equivalent quarter of 2003, with the estimation taking the actual values of the other exogenous variables. The contribution of this variable was obtained as the difference between the two series. The same procedure was applied for all the exogenous variables. 
Figure 6 presents the results. When the differences take positive values, it means that the unemployment rate would have been higher if the exogenous variable had kept its 2003 values and not evolved as it did. According to this exercise, the increases in capital productivity and capital accumulation made a substantial contribution to the recent trajectory of unemployment. This means that if the capital stock and capital productivity had not moved upward but had held steady at their 2003 levels, the unemployment rate would have fallen by less than it did, ending the period 3.7 and 7.5 percentage points above the level actually attained, respectively. ${ }^{19}$

Figure 6

Contribution of exogenous variables to the drop in the unemployment rate, 2003-2011 (Percentage points)

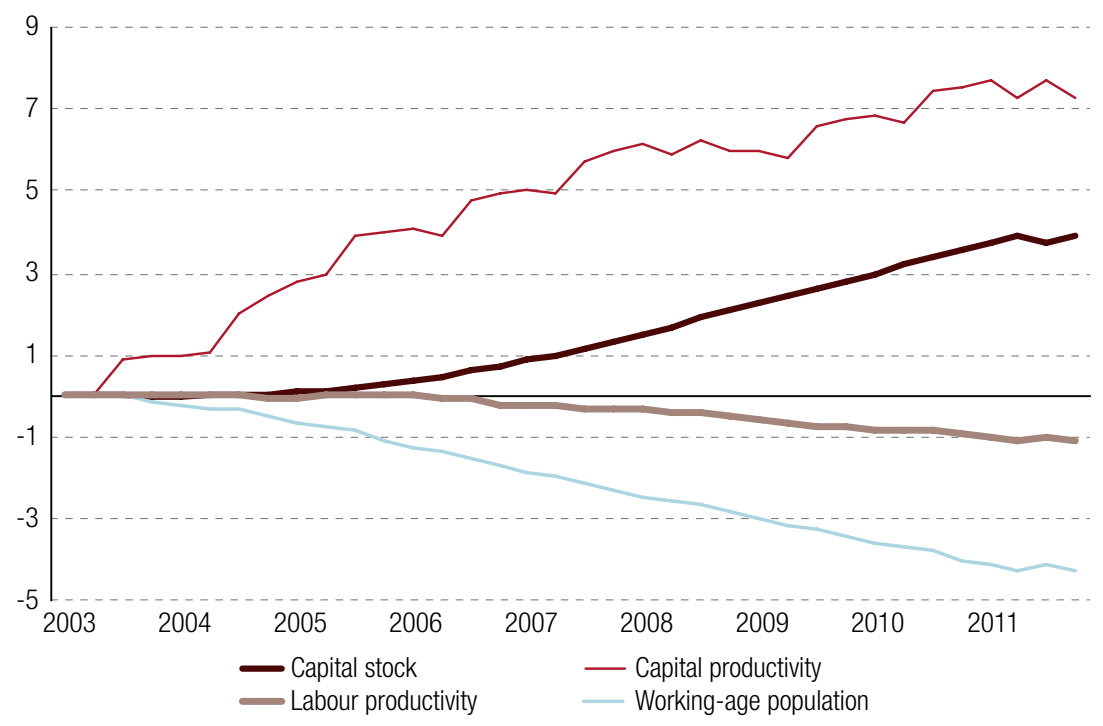

Source: Prepared by the authors.

The other variables had the opposite effect. The increase in the working-age population led to a rise in the labour supply, placing upward pressure on unemployment. If this variable had kept its 2003 level, the unemployment rate in 2011 would have been 4 percentage points lower. Labour productivity was another variable that rose in the period and placed direct upward pressure on wages even as it indirectly influenced demand and supply changes, so that it also exerted upward pressure on unemployment, albeit to a much lesser extent than the rise in the working-age population.

In summary, it can be said that the developments illustrated by figure 6 are consistent with expectations. It shows that the growth in capital stock and capital productivity in Uruguay, combined with the complementarity of labour market adjustments, can explain much of the substantial drop in the unemployment rate between 2003 and 2011.

\section{Conclusions}

Chain reaction theory was applied to study the dynamics of unemployment in Uruguay in the period from 1985 to 2011, and the evidence supplied helps to explain the determinants of the unemployment level and the decline in the unemployment rate from 2003 onward.

19 The level actually attained is not the one actually observed, but the one arrived at by estimating the system as a whole. 
First, the major labour market variables, namely demand, supply and wage formation, were found to present inertia and, being interconnected, spillover effects. The result is that one-off shocks to any of the labour market variables have effects on unemployment that take time to dissipate. For example, if the shock is from demand or supply, there are effects on unemployment that persist for 11 quarters and 8 quarters, respectively, while if the shock is from wages, the effects linger for up to 5 years.

Second, adjustment processes operate in a complementary fashion, creating effects whereby the magnitude and persistence of shocks expand. If there were no such complementarity, a oneoff shock that increased the demand for labour by causing a 1 percentage point decline in the unemployment rate would dissipate in the fifth quarter, whereas in fact, as indicated, the effect lingers for 11 quarters.

Furthermore, one of the key contributions of chain reaction theory is that it can be used to detect the influence on the unemployment rate of changes in variables exogenous to the labour market. In particular, it was found that changes in the capital stock created persistent effects on unemployment, with these dissipating only after 3 to 7 years, depending on the type of shock.

With regard to the recent performance of unemployment in Uruguay, the reduction in unemployment levels was found to be accounted for essentially by two factors. First, among the exogenous variables, the most important effects were from the rise in capital productivity and the capital stock. If these variables had remained at their 2003 levels, the unemployment rate would have fallen by less, ending the period 3.7 and 7.5 percentage points, respectively, above the level actually attained. Second, a large proportion of the decline is explained by the spillover effects arising from the complementarity of the adjustment processes of Uruguayan labour market variables.

Lastly, the findings of this study have some important implications for both unemployment dynamics and the design of future policies. First, the inertia and complementarity found in the adjustment processes of labour market variables, together with the existence of spillover effects with persistent impacts, suggest that the unemployment rate does not converge on an invariant level. On the contrary, its long-term evolution appears to be determined by the unending sequence of nominal and real shocks and intertemporal propagation mechanisms. This takes away from the argument that current levels of employment (and low unemployment) are not sustainable over time. Karanassou, Sala and Salvador (2008) argue that different policies may be required to deal with shocks of differing durations and that chain reaction theory creates scope for applying policies to combat unemployment. For example, interventions designed to increase the capital stock and/or factor productivity could have persistent effects on the short- and long-run unemployment rate.

\section{Bibliography}

Badagián, A. and others (2001), "Tasa de desempleo de Montevideo: ¿raíz unitaria o cambio estructural?", Documentos de Trabajo series, No. DT (01/01), Montevideo, University of the Republic.

Bande, R. (2002), "Ajustes dinámicos en las tasas de paro: España vs. Portugal”, Análise Económica, No. 20, Galician Studies and Development Institute.

Bande R. and M. Karanassou (2009), "Labour market flexibility and regional unemployment rate dynamics: Spain 1980-1995", Papers in Regional Science, vol. 88, No. 1, Wiley Blackwell.

Borraz, F. and M. Tubio (2009), "La tasa natural de desempleo en Uruguay", Banco Central del Uruguay [online] www.bcu.gub.uy/autoriza/peiees/jor/2009/iees03j3601009.pdf.

González, I. and H. Sala (2011), "Macroeconomic consequences of the U.S. financialisation process: lower capital accumulation, higher unemployment" [online] http://www.ecap.uab.es/secretaria/trebrecerca/ Igonzalez.pdf.

Henry, B., M. Karanassou and D. Snower (2000), "Adjustment dynamics and the natural rate: an account of UK unemployment", Oxford Economic Papers, vol. 52, No. 1, Oxford University Press. 
Karanassou, M. (1998), "Unemployment dynamics: the chain reaction theory of unemployment", thesis, London, Birkbeck College, University of London.

Karanassou, M. and D. Snower (2004), "Unemployment invariance”, German Economic Review, vol. 5, No. 3, Wiley.

(2000), "Characteristics of unemployment dynamics: the chain reaction approach", IZA Discussion Paper, No. 127, Bonn, Institute for the Study of Labour (IZA).

(1998), "How labour market flexibility affects unemployment: long term implications of the chain reaction theory", The Economic Journal, vol. 108, No. 448, Wiley.

(1997), "Is the natural rate a reference point?", European Economic Review, vol. 41, No. 3-5, Amsterdam, Elsevier.

(1996), "Explaining disparities in unemployment dynamics", The 1990's Slump: Causes and Cures, M. Baldassari, L. Paganetto and E. Phelps (eds.), London, Palgrave Macmillan.

Karanassou, M. and H. Sala (2010), "Labour market dynamics in Australia: what drives unemployment?", Economic Record, vol. 86, No. 273, The Economic Society of Australia.

(2008), "The rise and fall of Spanish unemployment: a chain reaction theory perspective", Working Paper, No. 273, Queen Mary University of London.

Karanassou, M., H. Sala and F. Salvador (2008), "The (ir)relevance of the NRU for policy making: the case of Denmark”, Scottish Journal of Political Economy, vol. 55, No. 3, Scottish Economic Society.

Karanassou, M., H. Sala and D. Snower (2009), "Phillips curves and unemployment dynamics: a critique and a holistic perspective", Journal of Economic Surveys, vol. 23, No. 4.

(2003), "Unemployment in the European Union: a dynamic reappraisal”, Economic Modelling, vol. 20, No. 2, Amsterdam, Elsevier.

Layard, R., S. Nickell and R. Jackman (1991), Unemployment: Macroeconomic Performance and the Labour Market, Oxford, Oxford University Press.

Leites, M. and S. Porras (2013), "El enfoque de la reacción en cadena: una aplicación para explicar la dinámica del desempleo en Uruguay", Documentos de Trabajo series, No. DT 11/2013, Montevideo, University of the Republic.

Montuenga, V. and V. Ramos (2005), "Reconciling the wage curve and the Phillips curve", Journal of Economic Surveys, vol. 19, No. 5, Wiley.

Pesaran, H. (1997), "The role of economic theory in modelling the long run", The Economic Journal, vol. 107, No. 440, Wiley.

Pesaran, H. and Y. Shin (1995), "An autoregresive distributed lag modelling approach to cointegration analysis", DEA Working Paper, No. 9514.

Pesaran, H., Y. Shin and R. Smith (2001), "Bounds testing approaches to the analysis of level relationships", Journal of Applied Econometrics, vol. 16, No. 3, Wiley. (1996), "Testing for the existence of a long run relationship", CREST Working Paper, No. 9645.

Phelps, E.S. (1994), Structural Slumps, Cambridge, Massachusetts, Harvard University Press.

Rodríguez, S. (1998), "Modelización y desestacionalización de la tasa de desempleo de Montevideo", paper presented at the XIII Annual Meeting of Economics of the Central Bank of Uruguay.

Román, C. and H. Willebald (2012), "Indicadores de inversión en el largo plazo. Una propuesta para Uruguay (1870-2011)", Working Paper, No. 12-21, Montevideo, University of the Republic.

Spremolla, A. (2001), "Persistencia en el desempleo de Uruguay", Cuadernos de Economía, vol. 32, No. 113, Santiago, Institute of Economics, Catholic University of Chile.

Taylor, J. (1979), "Staggered wage setting in a macro model", American Economic Review, vol. 69, No. 2, Nashville, Tennessee, American Economic Association.

Weller, J. (2014), "Aspects of recent developments in the Latin American and Caribbean labour markets", CEPAL Review, No. 114 (LC/G.2629-P), Santiago, Economic Commission for Latin America and the Caribbean (ECLAC).

World Bank (2012), The Labor Market Story behind Latin America's Transformation, Washington, D.C. 


\section{Annex A1}

TABLE A1.1

Description of the variables used

\begin{tabular}{|c|c|c|c|}
\hline & & & Source \\
\hline \multicolumn{4}{|c|}{ Endogenous variables } \\
\hline$l_{t}$ & Log active population ${ }^{\mathrm{a}}$ & & INE \\
\hline$n_{t}$ & Log working population ${ }^{\mathrm{a}}$ & & INE \\
\hline$u_{t}$ & Unemployment rate & & $\left(l_{t}-n_{t}\right)$ \\
\hline$w_{t}$ & Log real wage & & INE \\
\hline \multicolumn{4}{|c|}{ Exogenous and control variables } \\
\hline$k_{t}$ & Log capital stock ${ }^{b}$ & & IECON \\
\hline prk $_{t}$ & Log capital productivityc & & $\mathrm{BCU} / \mathrm{ECON}$ \\
\hline$z_{t}$ & Log working-age populationo ${ }^{d}$ & & INE \\
\hline $\mathrm{prn}_{t}$ & Log labour productivity ${ }^{\mathrm{e}}$ & & $\mathrm{BCU} / \mathrm{INE}$ \\
\hline \multicolumn{4}{|c|}{ Dummy variables } \\
\hline$d 1$ & 2002, third quarter & $=1$ economic crisis & \\
\hline$d 2$ & 1997, first quarter & $=1$ outlying value in series $n_{t}$ and $l_{t}$ & \\
\hline$d 3$ & 2000, second quarter & $=1$ outlying value in series $n_{t}$ and $l_{t}$ & \\
\hline$d 4$ & 1994, fourth quarter & $=1$ outlying value in series $l_{t}$ & \\
\hline$d 5$ & 1987, third quarter & $=1$ outlying value in series $l_{t}$ & \\
\hline$d 6$ & $\geq 2002$, third quarter & $=1$ exit from crisis and economic recovery & \\
\hline$d 7$ & 1990 , first to fourth quarter & $=1$ high inflation, drop in real wage & \\
\hline$d 8$ & 1993, first quarter & $=1$ outlying value in series $w_{t}$ & \\
\hline$d 9$ & 1987, fourth quarter & $=1$ outlying value in series $w_{t}$ & \\
\hline
\end{tabular}

Source: National Institute of Statistics (INE), Central Bank of Uruguay (BCU) and Institute of Economics (IECON) of the University of the Republic, Uruguay.

a The series were constructed from the activity and employment rates given by the continuous household surveys and INE population projections.

b See Román and Willebald (2012) for a description of how this annual capital stock series is prepared. The data were converted into quarterly equivalents using a constant depreciation rate and quarterly investment information.

c This derives from the ratio between real gross domestic product (GDP) and capital stock.

d INE single-age population projections.

e This derives from the ratio between GDP and total hours worked. 
TABLE A1.2

F-test for the long-run relationship between variables

\begin{tabular}{|c|c|c|c|c|c|c|}
\hline \multicolumn{7}{|c|}{ Labour demand } \\
\hline \multicolumn{7}{|c|}{$\Delta n_{t}=a_{1} n_{t-1}+a_{2} w_{t-4}+a_{3} k_{t-1}+a_{4} p r k_{t-1}+\sum a_{n i} \Delta n_{t-i}+\sum a_{w 4}-i \Delta w_{t-4-i}+\sum a_{k i} \Delta k_{t-i}+\sum a_{p r k i} \Delta p r k_{t-i}+a_{0}$} \\
\hline Lags & & 1 & 2 & 3 & 4 & 5 \\
\hline \multirow{2}{*}{ Selection criteria } & Akaike & $-5.55^{*}$ & -5.49 & -5.45 & -5.41 & -5.41 \\
\hline & Schwarz & $-5.27^{*}$ & -5.09 & -4.96 & -4.81 & -4.70 \\
\hline \multirow{2}{*}{ Autocorrelation tests ${ }^{\mathrm{a}}$} & $\operatorname{SC}\left[\chi^{2}(1)\right]$ & 0.51 & 0.83 & 0.75 & 0.64 & 0.17 \\
\hline & $\operatorname{SC}\left[\chi^{2}(4)\right]$ & 0.83 & 0.86 & 0.65 & 0.40 & 0.19 \\
\hline \multirow{2}{*}{ F-test $\left(H_{0}: a_{1}=a_{2}=a_{3}=a_{4}=0\right)^{b}$} & Statistic & 5.40 & 3.73 & 2.96 & 2.42 & 2.63 \\
\hline & Significance & $\star \star$ & & & & \\
\hline \multirow{2}{*}{ t-test $\left(H 0: a_{1}=0\right)^{c}$} & Statistic & -3.52 & -2.98 & -3.13 & -2.96 & -2.72 \\
\hline & Significance & * & & & & \\
\hline \multicolumn{7}{|c|}{ Labour supply } \\
\hline \multicolumn{7}{|c|}{$\Delta l_{t}=b_{1} l_{t-1}+b_{2} w_{t-1}+b_{3} u_{t-1}+b_{4} z_{t-1}+\sum b_{l i} \Delta l_{t-i}+\sum b_{w i} \Delta w_{t-i}+\sum b_{u i} \Delta u_{t-i}+\sum b_{z i} \Delta z_{t-i}+b_{0}$} \\
\hline Lags & & 1 & 2 & 3 & 4 & 5 \\
\hline \multirow{2}{*}{ Selection criteria } & Akaike & $-5.83^{*}$ & -5.79 & -5.73 & -5.67 & -5.63 \\
\hline & Schwarz & $-5.52^{*}$ & -5.38 & -5.22 & -5.05 & -4.91 \\
\hline \multirow{2}{*}{ Autocorrelation tests ${ }^{\mathrm{a}}$} & $S C\left[\chi^{2}(1)\right]$ & 0.97 & 0.64 & 0.39 & 0.54 & 0.94 \\
\hline & $\operatorname{SC}\left[\chi^{2}(4)\right]$ & 0.56 & 0.60 & 0.30 & 0.46 & 0.59 \\
\hline \multirow{2}{*}{ F-test $\left(H 0: b_{1}=b_{2}=b_{3}=b_{4}=0\right)^{b}$} & Statistic & 5.25 & 3.55 & 3.20 & 2.33 & 2.57 \\
\hline & Significance & ** & & & & \\
\hline \multirow{2}{*}{ t-test $\left(\mathrm{HO}: b_{1}=0\right)^{c}$} & Statistic & -4.40 & -3.41 & -2.92 & -2.28 & -2.34 \\
\hline & Significance & $* \star \star *$ & & & & \\
\hline \multicolumn{7}{|c|}{ Wages } \\
\hline \multicolumn{7}{|c|}{$\Delta w_{t}=c_{1} w_{t-1}+c_{2} p r n_{t-1}+c_{3} u_{t-1}+\sum c_{w i} \Delta w_{t-i}+\sum c_{p r n i} \Delta p r n_{t-i}+\sum c_{u i} \Delta u_{t-i}+c_{0}$} \\
\hline Lags & & 1 & 2 & 3 & 4 & 5 \\
\hline \multirow{2}{*}{ Selection criteria } & Akaike & -5.38 & $-5.41^{*}$ & -5.40 & -5.37 & -5.38 \\
\hline & Schwarz & $-5.10^{*}$ & -5.05 & -4.97 & -4.86 & -4.79 \\
\hline \multirow{2}{*}{ Autocorrelation tests ${ }^{\mathrm{a}}$} & $S C\left[\chi^{2}(1)\right]$ & 0.79 & 0.61 & 0.51 & 0.74 & 0.39 \\
\hline & $\operatorname{SC}\left[\chi^{2}(4)\right]$ & 0.37 & 0.73 & 0.75 & 0.63 & 0.38 \\
\hline \multirow{2}{*}{ F-test $\left(\mathrm{HO}: \mathrm{C}_{1}=\mathrm{C}_{2}=\mathrm{C}_{3}=0\right)^{\mathrm{d}}$} & Statistic & 19.48 & 13.31 & 11.35 & 10.94 & 12.82 \\
\hline & Significance & $* \star \star *$ & $* \star \star$ & $* \star \star$ & $* \star *$ & $* * *$ \\
\hline \multirow{2}{*}{ t-test $\left(\mathrm{HO}: \mathrm{C}_{1}=0\right)^{\mathrm{e}}$} & Statistic & -6.62 & -5.73 & -4.89 & -4.65 & -5.29 \\
\hline & Significance & 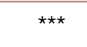 & 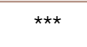 & 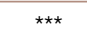 & *** & 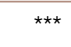 \\
\hline
\end{tabular}

Source: Prepared by the authors.

a $p$-value.

b Critical values for $90 \%\left(^{\star}\right): 2.72-3.77$; for $95 \%\left(^{\star \star)}\right): 3.23-4.35$; for $99 \%\left(^{* \star \star)}\right): 4.29-5.61$.

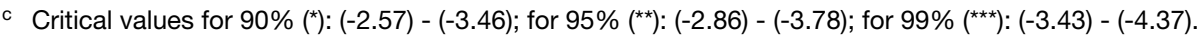

d Critical values for $90 \%\left({ }^{\star}\right): 3.17-4.14$; for $95 \%\left(^{* \star}\right): 3.79-4.85$; for $99 \%\left(^{* \star *}\right): 5.15-6.36$.

e Critical values for $90 \%\left(^{*}\right):(-2.57)-(-3.21)$; for $95 \%\left(^{* \star}\right):(-2.86)-(-3.53)$; for $99 \%\left(^{* \star *}\right):(-3.43)-(-4.10)$. 
TABLE A1.3

System equation specification tests $^{a}$

\begin{tabular}{|c|c|c|c|c|c|}
\hline \multicolumn{6}{|c|}{ Estimations with instrumental variables ${ }^{b}$} \\
\hline \multicolumn{2}{|c|}{ Labour demand } & \multicolumn{2}{|c|}{ Labour supply } & \multicolumn{2}{|c|}{ Wages } \\
\hline $\operatorname{NOR}\left[\chi^{2}(2)\right]$ & 0.925 & $\operatorname{NOR}\left[\chi^{2}(2)\right]$ & 0.845 & $\operatorname{NOR}\left[\chi^{2}(2)\right]$ & 0.408 \\
\hline $\operatorname{SC}\left[\chi^{2}(1)\right]$ & 0.854 & $\operatorname{SC}\left[\chi^{2}(1)\right]$ & 0.087 & $\operatorname{SC}\left[\chi^{2}(1)\right]$ & 0.538 \\
\hline$S C\left[\chi^{2}(4)\right]$ & 0.788 & $\operatorname{SC}\left[\chi^{2}(4)\right]$ & 0.043 & $\operatorname{SC}\left[\chi^{2}(4)\right]$ & 0.543 \\
\hline $\operatorname{HET}\left[\chi^{2}(6)\right]$ & 0.295 & $\operatorname{HET}\left[\chi^{2}(8)\right]$ & 0.148 & $\operatorname{HET}\left[\chi^{2}(7)\right]$ & 0.120 \\
\hline
\end{tabular}

Source: Prepared by the authors.

a The values presented are the $p$-values for the normality tests (NOR), serial correlation with one and four lags (SC) and heteroskedasticity (HET).

b Instrumental variables: $n_{t-1}, l_{t-1}, w_{t-1}, w_{t-4}, w_{t-5}, k_{t-1}, k_{t-2}, p r k_{t-1}, p r k_{t-2}, \Delta p r k_{t}, \Delta p r k_{t-1}, u_{t-1}, u_{t-2}, u_{t-3}, u_{t-4}, \Delta w_{t}, \Delta w_{t-1}, \Delta w_{t-2}$, $z_{t-1}, z_{t-2}, z_{t-3}, \operatorname{prn}_{t-1}, \operatorname{prn}_{t-2}, \Delta p r n_{t-1}, \Delta p r n_{t-2}, d 1, d 2, d 3, d 4, d 5, d 6, d 7, d 8, d 9$ and $c$. 